\title{
Necroptosis Contributes to Urban Particulate Matter-Induced Airway Epithelial Injury
}

\author{
Feng Xua Man Luo Lulu He ${ }^{a}$ Yuan Cao ${ }^{a}$ Wen Lia Songmin Ying ${ }^{a}$ Zhihua Chen $^{a}$ \\ Huahao Shen ${ }^{a, b}$
}

aKey Laboratory of Respiratory Disease of Zhejiang Province, Department of Respiratory and Critical Care Medicine, Second Affiliated Hospital of Zhejiang University School of Medicine, Hangzhou, 'bState Key Laboratory of Respiratory Disease, Guangzhou, China

\section{Key Words}

Particulate matter • Necroptosis • Airway inflammation • Mucus hyperproduction

\begin{abstract}
Background/Aims: Necroptosis, a form of programmed necrosis, is involved in the pathologic process of several kinds of pulmonary diseases. However, the role of necroptosis in particulate matter (PM)-induced pulmonary injury remains unclear. The objective of this study is to investigate the involvement of necroptosis in the pathogenesis of PM-induced toxic effects in pulmonary inflammation and mucus hyperproduction, both in vitro and in vivo. Methods: PM was administered into human bronchial epithelial (HBE) cells or mouse airways, and the inflammatory response and mucus production were assessed. The mRNA expressions of IL6, IL8 and MUC5AC in HBE cells and Cxcl1, Cxcl2, and Gm-csf in the lung tissues were detected by quantitative real-time RT-PCR. The secreted protein levels of IL6 and IL8 in culture supernatants and $\mathrm{CxCl} 1, \mathrm{CxCl} 2$, and $\mathrm{Gm}$-csf in bronchoalveolar lavage fluid (BALF) were detected by enzyme-linked immunosorbent assay (ELISA). We used Western blot to measure the protein expressions of necroptosis-related proteins (RIPK1, RIPK3, and PhosphoMLKL), NF-KB (P65 and PP65), AP-1 (P-C-Jun and P-C-Fos) and MUC5AC. Cell necrosis and mitochondrial ROS were detected using flow cytometry. In addition, pathological changes and scoring of lung tissue samples were monitored using hemoxylin and eosin (H\&E), periodic acid-schiff (PAS) and immunohistochemistry staining. Results: Our study showed that PM exposure induced RIP and MLKL-dependent necroptosis in HBE cells and in mouse lungs. Managing the necroptosis inhibitor Necrostatin-1 (Nec-1) and GSK'872, specific molecule inhibitors of necroptosis, markedly reduced PM-induced inflammatory cytokines, e.g., IL6 and IL8, and MUC5AC in HBE cells. Similarly, administering Nec-1 significantly reduced airway inflammation and mucus hyperproduction in PM-exposed mice. Mechanistically, we found PM-induced necroptosis was mediated by mitochondrial reactive oxygen species-dependent early growth response gene 1 , which ultimately promoted inflammation and mucin expression
\end{abstract}

Huahao Shen and Zhihua Chen

KARGER
Key Laboratory of Respiratory Disease of Zhejiang Province, Department of Respiratory and Critical Care Medicine, Second Affiliated Hospital of Zhejiang University School of Medicine, Hangzhou, 310009 (China); State Key Laboratory of Respiratory Disease, Guangzhou, 510000 (China); E-Mail huahaoshen@zju.edu.cn and zhihuachen@zju.edu.cn 


\section{Cellular Physiology Cell Physiol Biochem 2018;46:699-712

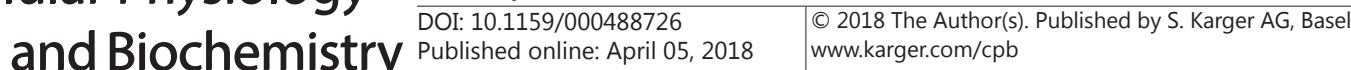 \\ Xu et al.: Necroptosis Contributes to PM-Induced Airway Epithelial Injury}

through nuclear factor $\mathrm{KB}$ and activator protein-1 pathways, respectively. Conclusions: Our results demonstrate that necroptosis is involved in the pathogenesis of PM-induced pulmonary inflammation and mucus hyperproduction, and suggests that it may be a novel target for treatment of airway disorders or disease exacerbations with airborne particulate pollution.

(C) 2018 The Author(s)

Published by S. Karger AG, Basel

\section{Introduction}

Airborne particulate matter (PM) poses strong influences on the climate, environment and public health [1-3]. PM exposure has been shown to be a major risk factor for acute and chronic diseases including cardiovascular disease, liver fibrosis, various gastrointestinal diseases, and chronic respiratory disease, such as asthma and chronic obstructive pulmonary disease (COPD), along with lung cancer [4-8]. The sources of PM are complex and include transportation (e.g., vehicle exhaust), factory emissions (e.g., industries and coal-fired power plants), combustion (e.g., biomass and cigarette smoke) and agriculture (e.g., fertilizer and animal waste), and natural sources (e.g., volcanoes, forest fires and dust storms) [5]. Regardless of the origin, PM is a widespread air pollutant containing various toxins such as carbonaceous cores, polycyclic aromatic hydrocarbons (PAHs), quinones, metals, endotoxins, and many others [9]. Thus, elevated levels of short- and long-term PM exposure can induce many diseases associated with increased morbidity and mortality. It is important to find the molecular mechanisms and therapeutic targets in PM-induced pulmonary injury.

Apoptosis and necrosis are two major types of cell death. However, apoptosis is a programmed cell death modality, generally triggered by physiological processes, whereas necrosis is an uncontrolled and accidental cell death modality triggered by pathological processes. Necroptosis, a novel cell death modality, involves the loss of membrane integrity and occurs by a programmable mechanism with a characteristic necrotic cell death phenotype [10-13]. Necroptosis is initiated by the activation of receptor interacting protein (RIP) kinases and mixed-lineage kinase domain-like protein (MLKL). This leads to a loss of cellular integrity via the release of cytoplasmic content and the exposure of damageassociated molecular patterns (DAMPs) (e.g., high-mobility group box 1 [HMGB1], doublestranded DNA, heat shock protein 70, mitochondrial DNA, and ATP) [14-16]. Accumulating evidence suggested that necroptosis played an important role in the pathogenesis of pulmonary diseases [17]. One recent study described how the level of RIPK3, the hallmark of the activation of necroptosis, was increased in COPD lung tissue, and thus contributed to COPD pathogenesis [18]. Duprez also revealed that the inhibitor of RIPK1 (Nec-1) or deletion of RIPK3 (RIPK3 deficiency) could protect against systemic inflammatory response syndrome (SIRS) and sepsis [19]. Moreover, in lung cancer treatment, necroptosis exerted important roles in anti-tumor effect [20]. However, the functions and detailed mechanisms of necroptosis in PM-related pulmonary disorders still remain largely unknown.

The objective of this study is to investigate whether PM induces necroptosis in airway epithelium, and to understand its function in PM-induced epithelial injury. The upstream and downstream signals of PM-induced necroptosis are also explored.

\section{Materials and Methods}

\section{Cell Culture}

HBE human bronchial epithelial cells were cultured in RPMI 1640 supplemented with 10\% fetal bovine serum (FBS) and $1 \%$ penicillin-streptomycin at $37^{\circ} \mathrm{C}$ in a water-saturated atmosphere with $5 \% \mathrm{CO}_{2}$. The cells were incubated with the following reagents, Nec-1 (25 $\mu$ M, Sigma, USA), GSK'872 (5 $\mu$ M, Selleck, USA), standard reference airborne PM (standard reference material 1649b, obtained from National Institute of Standards and Technology, Gaithersburg, MD, USA), and mito-TEMPO (10 $\mu$ M, Alexis-Biochemicals, San Diego, CA, USA). 


\section{Cellular Physiology Cell Physiol Biochem 2018;46:699-712 \begin{tabular}{l|l} 
DOI: 10.1159/000488726 & Ond 2018 The Author(s). Published by S. Karger AG, Basel \\
www.karger.com/cpb
\end{tabular} \\ Xu et al.: Necroptosis Contributes to PM-Induced Airway Epithelial Injury}

Table 1. Primers used for quantitative real time PCR analysis

\begin{tabular}{|c|c|c|c|}
\hline Species & Genes & Primer sequence $\left[5^{\prime}-3^{\prime}\right]$ & \\
\hline Human & IL8 & Forward: ACTGAGAGTGATTGAGAGTGGAC & Reverse: AACCCTCTGCACCCAGTTTTC \\
\hline Human & IL6 & Forward: ACTCACCTCTTCAGAACGAATTG & Reverse: CCATCTTTGGAAGGTTCAGGTTG \\
\hline Mouse & Cxcl1 & Forward: CTGGGATTCACCTCAAGAACATC & Reverse: CAGGGTCAAGGCAAGCCTC \\
\hline Mouse & Cxcl2 & Forward: TGTCCCTCAACGGAAGAACC & Reverse: CTCAGACAGCGAGGCACATC \\
\hline Mouse & Gm-csf & Forward: CACAAGTTACCACCTATGC & Reverse: CAAGTTCCTGGCTCATTAC \\
\hline Mouse & Muc5ac & Forward: CTGTGACATTATCCCATAAGCCC & Reverse: AAGGGGTATAGCTGGCCTGA \\
\hline
\end{tabular}

Preparation of particle matter samples

We used standard reference airborne PM (average diameter: $10.5 \mu \mathrm{m}$ ), which primarily contains polycyclic aromatic hydrocarbons. PM was dispersed in phosphate buffered saline (PBS) or saline at a concentration of $2000 \mu \mathrm{g} / \mathrm{ml}$ (mass/volume). In vitro, PM was dispersed in sterile PBS, and pulmonary cells were treated with PM at $100 \mu \mathrm{g} / \mathrm{ml}$. In vivo, PM was dispersed in sterile saline at $100 \mu \mathrm{g} \mathrm{PM}$ (in $50 \mu \mathrm{l}$ saline) per day by intratracheal instillation.

Transfection with siRNAs

Control siRNA, Egr-1 siRNA, P65 siRNA, and Jun siRNA were purchased from Santa Cruz Biotechnology (Santa Cruz, CA, USA). Transfection of siRNA was carried out using the transfection reagent according to the manufacturer's instructions.

\section{RNA isolation and quantitative real-time PCR analysis}

Total RNA from lung tissues and treated cells was extracted using Trizol reagent (Invitrogen, Carlsbad, CA, USA), according to the manufacturer's protocol. The reverse transcriptase reaction was performed using Reverse Transcription Reagents (Takara Biotechnology, Shiga, Japan). The resulting cDNA was used for realtime RT-PCR using SYBR Green Master Mix (Takara Biotechnology, Shiga, Japan) on a StepOne realtime PCR system (Applied Biosystems, Foster City, CA, USA). The sequences of primer pairs are presented in Table 1.

Flow cytometry

After exposure to PM, cells were collected and stained with MitoSOX (Invitrogen, $5 \mu$ M for 15 min at $37^{\circ} \mathrm{C}$ ). Cell death was assessed with double staining with FITC-labeled Annexin-V in combination with PI (Multi Sciences, Hangzhou, China). Flow cytometry assays were performed according to the manufacturer's instructions.

\section{Western blot}

After exposure to PM, cells lysates and lung tissue homogenates were lysed in RIPA buffer containing protease and phosphatase inhibitors. For Western blot, equal amounts of protein for each group were subjected to sodium dodecyl sulfate polyacrylaminde gel electrophoresis (SDS-PAGE) and then transferred to polyvinylidene difluoride (PVDF) membrane. The PVDF membranes were then blocked at room temperature for $1 \mathrm{~h}$, and incubated for overnight in $4{ }^{\circ} \mathrm{C}$ with the following antibodies against the following proteins: $\beta$-actin (Sigma-Aldrich), Egr-1 (Cell Signaling Technology, Danvers, MA, USA), NF- $\kappa$ B P65 (Cell Signaling Technology, MA, USA), Phospho-NF-кB P65 (Cell Signaling Technology, MA, USA), Phospho-cFos (Cell Signaling Technology, MA, USA), Phospho-c-Jun (Cell Signaling Technology, MA, USA), MUC5AC (Abcam, MA, USA), RIPK1 (Cell Signaling Technology, MA, USA), RIPK3(Cell Signaling Technology, MA, USA), and Phospho-MLKL(Cell Signaling Technology, MA, USA). After washing in Tris-Buffered Saline and Tween 20 (TBST) three times (5 min each), membranes were incubated with the secondary antibody (1:1000 dilutions) at room temperature for $1 \mathrm{~h}$.

ELISA

Cell culture supernatants of IL8 and IL6 and BALF supernatants of CXCL1, CXCL2, and GM-CSF collected were used to determine protein levels. ELISA assays were performed using ELISA kits from R\&D Systems following the manufacturer's instructions.

\section{KARGER}




\section{Cellular Physiology Cell Physiol Biochem 2018;46:699-712 \begin{tabular}{ll|l} 
DOI: 10.1159/000488726 & and Biochemistry \\
Publisned online: April 05, 2018 & $\begin{array}{l}\text { O } 2018 \text { The Author(s). Published by S. Karger AG, Basel } \\
\text { www.karger.com/cpb }\end{array}$
\end{tabular} \\ Xu et al.: Necroptosis Contributes to PM-Induced Airway Epithelial Injury}

\section{Animal Experiments}

Experiments were conducted in accordance with the Ethical Committee for Animal Studies at Zhejiang University. The mice were maintained in individual ventilated cages under specific pathogenfree conditions. Male C57BL/6 mice (aged 6-8 weeks) were randomly divided into the different exposure groups ( $\mathrm{n}=5-8$ mice/group). Mice were exposed to PM treated with $100 \mu \mathrm{g}$ PM (in 50 $\mu$ l saline) per day by intratracheal instillation for $7 \mathrm{~d}$ using a method as previously described [4]. Nec-1 (5 mg/kg) was injected intraperitoneally before PM challenge. Control mice received the same volume of saline and DMSO instead of PM and Nec-1, respectively.

\section{Histological analysis}

The samples were stained by hemoxylin and eosin (H\&E) or periodic acid-schiff (PAS) and imaged under an Olympus BX53 inverted microscope (Olympus, Melville, NY, USA). We assessed inflammation according to published guidelines [21], and scored PAS-stained goblet cells in airway epithelium as described previously [22].

\section{Statistical analysis}

Statistical analysis of differences between the groups was performed using GraphPad Prism Program (GraphPad, San Diego, CA, USA). Data are expressed as mean \pm standard error of the mean (SEM). Comparisons between the two groups were calculated using the Mann-Whitney U test. For multiple groups, one-way analysis of variance followed by the Newman-Keuls test was used. P values $<0.05$ were considered to indicate statistical significance.

\section{Results}

PM exposure induces necroptosis in pulmonary epithelial cells as well as in mouse lungs

To address the possible role of necroptosis in PM-induced airway injury, we first examined the expression of necroptosis-related proteins in pulmonary epithelial cells and mouse lungs after being exposed to PM. As shown in Fig. 1A, western blot analysis revealed that the expression of necroptosis-related proteins (RIPK1, RIPK3, and Phospho-MLKL) were significantly increased in time-dependent induction after stimulation with PM. Consistently, these biomarkers were significantly enhanced in dose-dependently (Fig. 1B). Necroptosis markers were also expanded in mouse lungs after treatment with PM (Fig. 1C). Such findings corroborate that necroptosis represents a response to PM exposure in vivo and in vitro.

Necroptosis is required for the release of PM-induced inflammatory cytokines and mucin MUC5AC in HBE cells

We next explore whether necroptosis is required for the release of PM-induced inflammatory cytokines. Interestingly, we found that Nec-1 treatment significantly attenuated the mRNA levels of IL6 and IL8 induced by PM exposure (Fig. 2A and C). The secreted protein levels of IL6 and IL8 were also decreased in culture supernatants upon PM exposure (Fig. 2B and D). Similar to cytokines, Nec-1 treatment significantly reduces the expression of MUC5AC (Fig. 2E). We use the PI positive percentage to detect necrotic cells and determine whether Nec-1 can reduce HBE cell death after PM exposure. As shown in Fig. 2F-G, flow cytometry results showed that Nec-1 reduced the number of PI positive cells after PM exposure, and indicates that inhibiting necroptosis with NEC-1 in pulmonary cells may increase cell survival and decrease PM-induced inflammation and mucus production. To further emphasize the impact of necroptosis on PM-induced airway inflammation and mucus production, RIPK3 inhibitor GSK'872 was used in HBE before PM exposure. Similar to the effects of Nec-1, GSK'872 treatment significantly reduced the PM-induced expression of IL6 and IL8 at both mRNA and protein levels in HBE cells (Fig. 2H-K). As such, GSK'872 treatment markedly attenuated the PM-induced production of MUC5AC (Fig. 2L). Our results further suggest that necroptosis may contribute to a pathogenic process leading to PMinduced inflammation and mucus production in airway epithelial cells. 


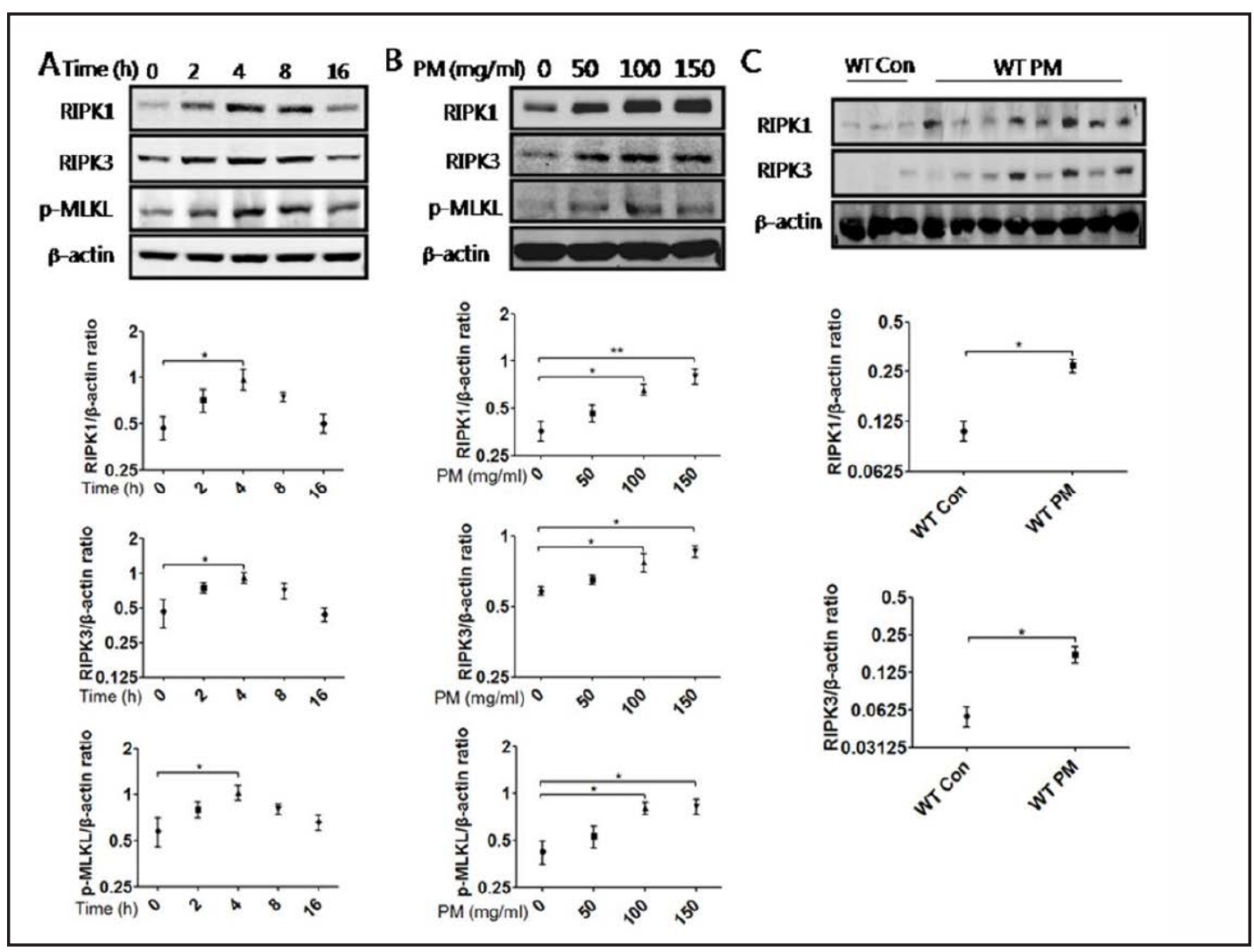

Fig. 1. PM exposure induces necroptosis in pulmonary epithelial cells as well as in mouse lungs. (A-B) Cells were exposed to PM at indicated times or concentrations. (A-B) Western blot analysis for a time course (PM at $100 \mu \mathrm{g} / \mathrm{ml}$ for various times) or dose response (various concentrations of PM for 4h) of RIPK1, RIPK3, and p-MLKL protein expression in HBE cells treated with PM. (C) Western blot analysis of RIPK1, RIPK3, and p-MLKL protein expression in lung tissues of WT mice treated with $100 \mu \mathrm{g}$ PM (in $50 \mu \mathrm{l}$ saline) by intratracheal instillation for $7 \mathrm{~d}$. The data are presented as the mean \pm SEM. ${ }^{*} \mathrm{P}<0.05$, ${ }^{* *} \mathrm{P}<0.01$, and ${ }^{* * *} \mathrm{P}<0.001$.

Necroptosis inhibitor Nec-1 attenuates PM-induced pulmonary inflammation in vivo

To elucidate the critical role of necroptosis in PM-induced pulmonary inflammation, we carried out in vivo experiments. In agreement with in vitro findings, treatment with Nec1 strongly decreased the PM-induced total number of inflammatory cells and neutrophils in bronchoalveolar lavage fluid (BALF) (Figs. 3A-B). Also, the PM-induced mRNA levels of inflammatory cytokines, such as Cxcl1, Cxcl2, and Gm-csf in the lung tissues (Figs. 3C, E, and G), and the protein levels of these inflammatory cytokines in the BALF (Figs. 3D, 3F, and $\mathrm{H}$ ) were very much affected by Nec- 1 treatment. Moreover, lung histopathology analysis also confirmed that the PM-induced airway inflammation was significantly affected in Nec-1 treated mice (Figs. 3I-J).

Necroptosis inhibitor Nec-1 lowers airway mucus production induced by PM exposure in vivo

We next sought to confirm the effect of necroptosis in the regulation of PM-induced mucus production in vivo. PAS staining and immunohistochemistry analysis of MUC5AC demonstrated less mucus production in Nec-1 treated mice (Figs. 4A-D). The mRNA levels of Muc5ac in the lungs were also reduced in response to PM exposure in Nec-1 treated mice (Fig. 4E). These findings suggest that inhibition of necroptosis lowers pulmonary mucus production as a result of PM exposure.

\section{KARGER}




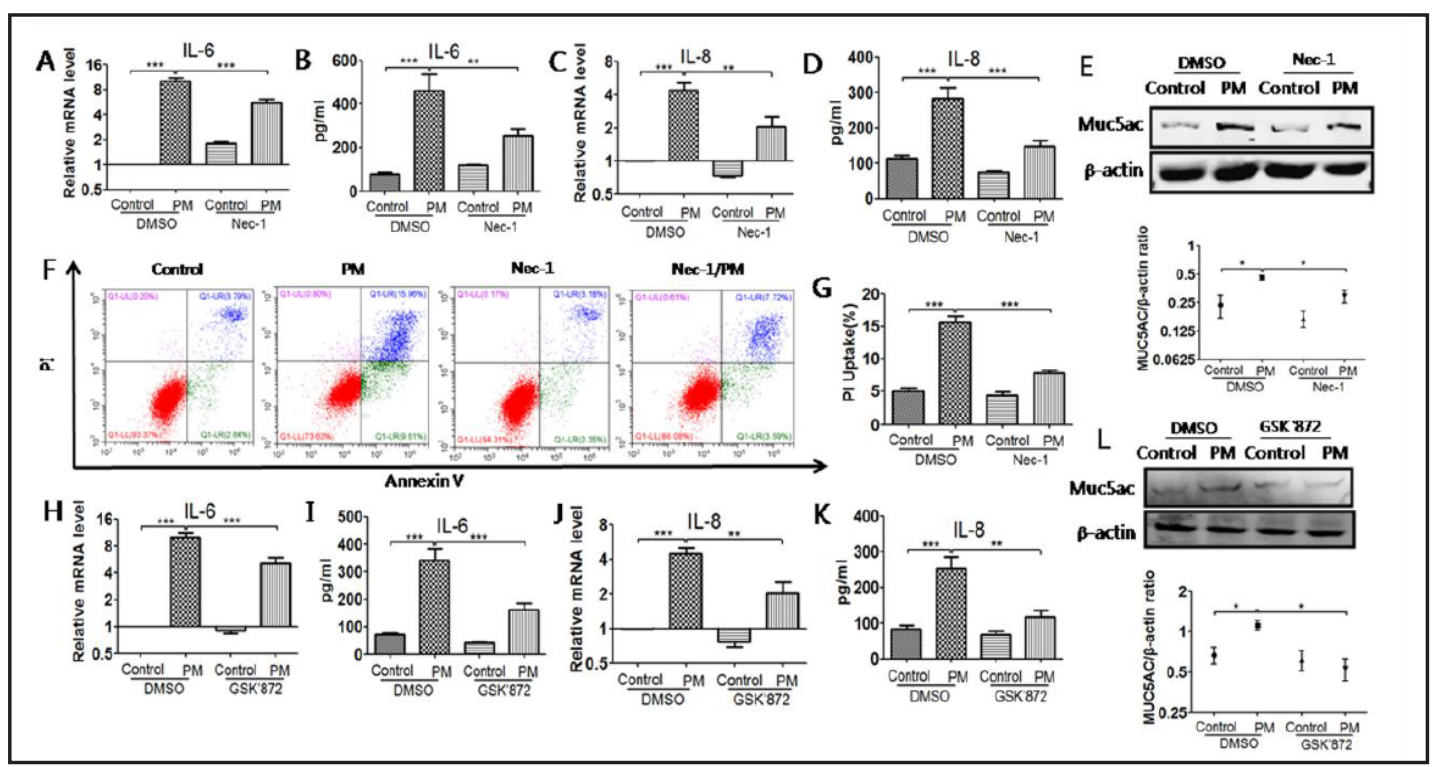

Fig. 2. Necroptosis is required for the release of PM-induced inflammatory cytokines and mucin MUC5AC in HBE cells. (A-D and F-G) Cells were incubated in the absence or presence of NEC-1, and then were treated with PM $(100 \mu \mathrm{g} / \mathrm{ml})$ for $24 \mathrm{~h}$. The relative levels of IL6 (A), and IL8 (C) mRNA transcripts were measured by quantitative RT-PCR, and the protein levels of IL6 (B) and IL8 (D) in the culture supernatants were measured by ELISA. (E) Cells were incubated in the absence or presence of NEC-1, and treated with PM $(100 \mu \mathrm{g} / \mathrm{ml})$ without FBS for an additional $48 \mathrm{~h}$ to measure the protein of MUC5AC via the Western blot.

(F) Representative graphs of cell death through flow cytometry analysis after Annexin-V/PI dual staining. (G) Statistical analysis of PI positive cell ratio. (H-K) Cells incubated in the absence or presence of GSK'872, and treated with PM (100 $\mu \mathrm{g} / \mathrm{ml})$ for $24 \mathrm{~h}$. The relative levels of IL6 (H), and IL8 (J) mRNA transcripts were measured by quantitative RT-PCR, and the protein levels of IL6 (I) and IL8 (K) in the culture supernatants, which are in turn were measured by ELISA. (L) Cells were incubated in the absence or presence of GSK'872, and then were treated with PM $(100 \mu \mathrm{g} / \mathrm{ml})$ without FBS for an additional $48 \mathrm{~h}$ to measure the protein of MUC5AC by Western blot. The data are presented as the mean \pm SEM. ${ }^{*} \mathrm{P}<0.05$, ${ }^{* *} \mathrm{P}<0.01$, and ${ }^{* * *} \mathrm{P}<0.001$.

MitoROS-dependent Egr-1 activation is involved in PM-induced necroptosis

We then examined the involvement of mitoROS and the early growth response gene 1 (Egr-1) in PM-induced necroptosis expression in HBE cells. As illustrated in Figs. 5A-B, flow cytometric analysis of mitoSOX demonstrated that higher levels of mitochondrial ROS were generated after PM exposure. Furthermore, PM exposure resulted in a time-dependent increase in Egr-1 (Fig. 5C). Specific inhibition of mitoROS by mitochondria-targeting antioxidant mito-TEMPO effectively downregulated PM-induced Egr-1 (Fig. 5D), and also attenuated PM-induced activation of RIPK1, RIPK3, and Phospho-MLKL (Fig. 5E) in HBE cells. Genetic inhibition of Egr-1 by siRNA significantly decreased PM-induced RIPK1, RIPK3, and Phospho-MLKL (Fig. 5F). These results suggest that PM-induced necroptosis in HBE cells can be mediated, at least in part, by mitoROS-dependent Egr-1 activation.

\section{$N F-\kappa B$ is critical for PM-induced inflammatory responses in HBE cells}

These intriguing results encouraged further exploration of the possible mechanisms in PM-induced expression of IL6 and IL8. Interestingly, we noted that inhibition of the NF$\kappa \mathrm{B}$ pathway by P65 siRNA reduced the PM-induced expression of IL6 and IL8 at mRNA, as well as protein levels in HBE cells (Figs. 6A-D). As seen in Fig. 6E, PM exposure resulted

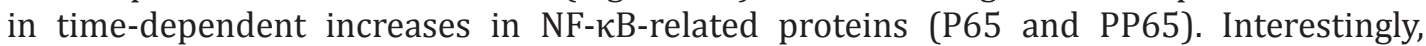
mito-TEMPO effectively lowered the PM-induced NF- $\mathrm{kB}$ activation (Fig. 6F). Furthermore, genetic inhibition of Egr-1 by siRNA or Nec-1 treatment dramatically decreased the PM- 


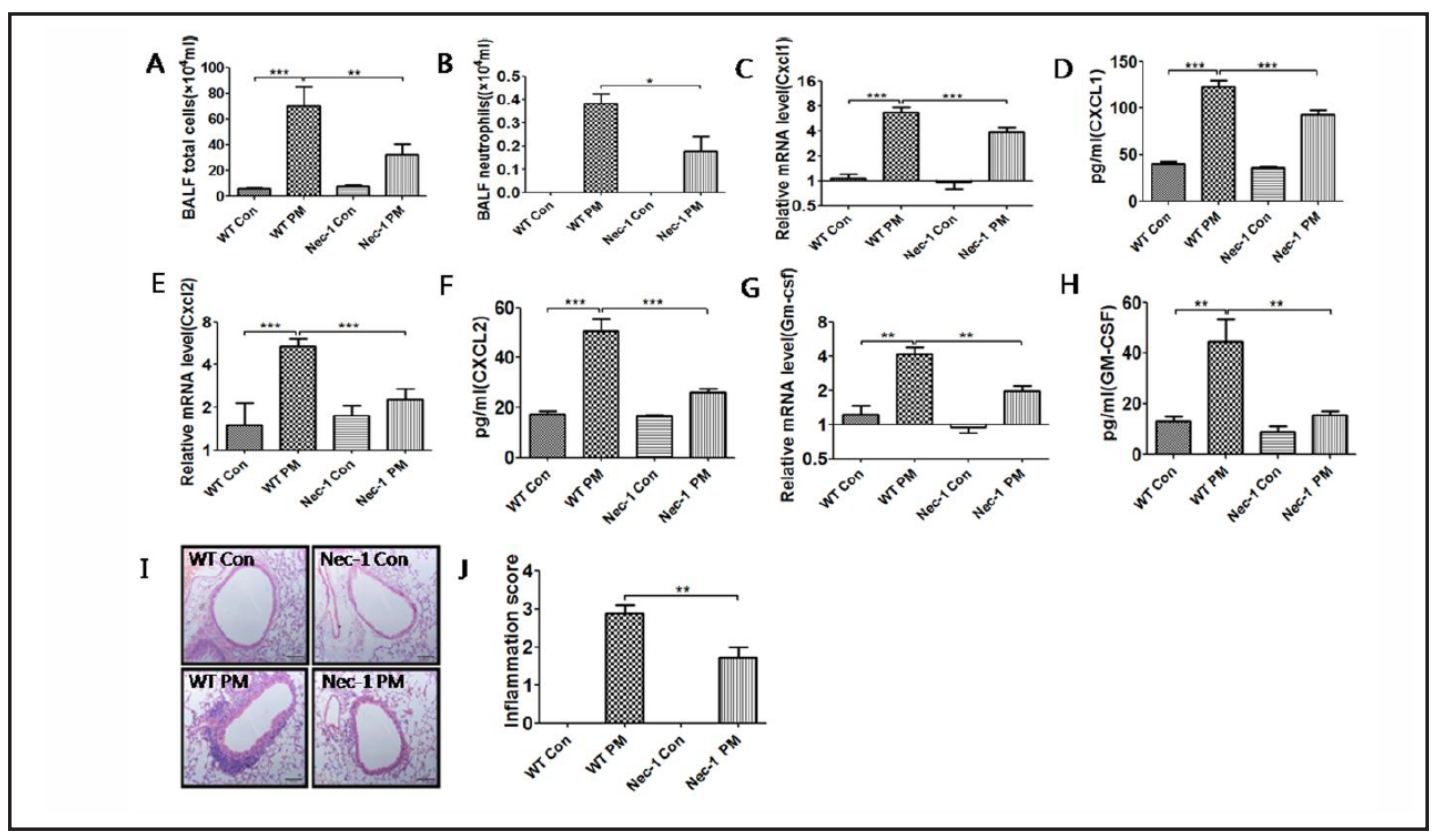

Fig. 3. Necroptosis inhibitor Nec-1 attenuates PM-induced pulmonary inflammation in vivo. Mice were anesthetized and instilled intratracheally with PM at $100 \mu \mathrm{g} / \mathrm{d}$ for $7 \mathrm{~d}$. After $24 \mathrm{~h}$, mice were sacrificed and the total inflammatory cells (A) and the number of neutrophils (B) in the BALF were measured. Expression of the mRNA levels of $\mathrm{Cxcl} 1(\mathrm{C}), \mathrm{Cxcl} 2(\mathrm{E})$, and $\mathrm{Gm}$-csf $(\mathrm{G})$ in lung tissues were assessed by quantitative PCR. Expression of the protein levels of CXCL1 (D), CXCL2 (F), and GM-CSF (H) in the BALF were measured by ELISA. (I) Lung sections stained with H\&E were performed to assess lung inflammation. (J) Semiquantified inflammation by H\&E staining. The data are presented as the mean $\pm \mathrm{SEM}$. ${ }^{*} \mathrm{P}<0.05, * * \mathrm{P}<0.01$, and ${ }^{* * *} \mathrm{P}$ $<0.001$.

Fig. 4. Necroptosis inhibitor Nec-1 lowers airway mucus production induced by PM exposure in vivo. (A) Representative images of lung sections with PAS staining. (B) Semiquantified PAS score. (C) Immunohistochemical staining was assessed with MUC5AC. (D) Quantification percentage of MUC5AC positive cells in the epithelium. (E) The mRNA expression of Muc5ac in lung tissue. The data are presented as the mean \pm SEM. ${ }^{*} \mathrm{P}<0.05$, ${ }^{* *} \mathrm{P}<0.01$, and ${ }^{* * *} \mathrm{P}<0.001$.

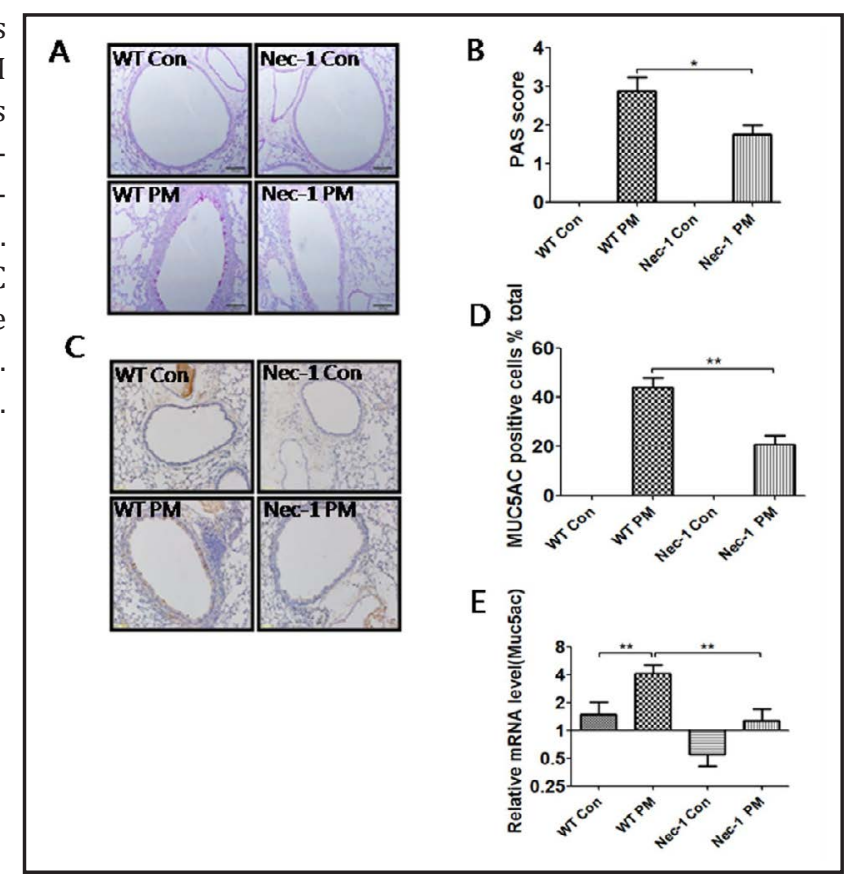

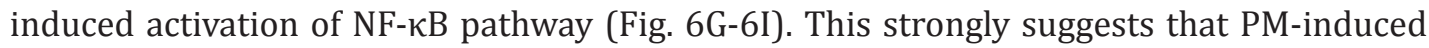
inflammation may be mediated via the mitoROS/Egr-1/necroptosis cascade, which then activates the NF- $\mathrm{\kappa B}$ pathway. 


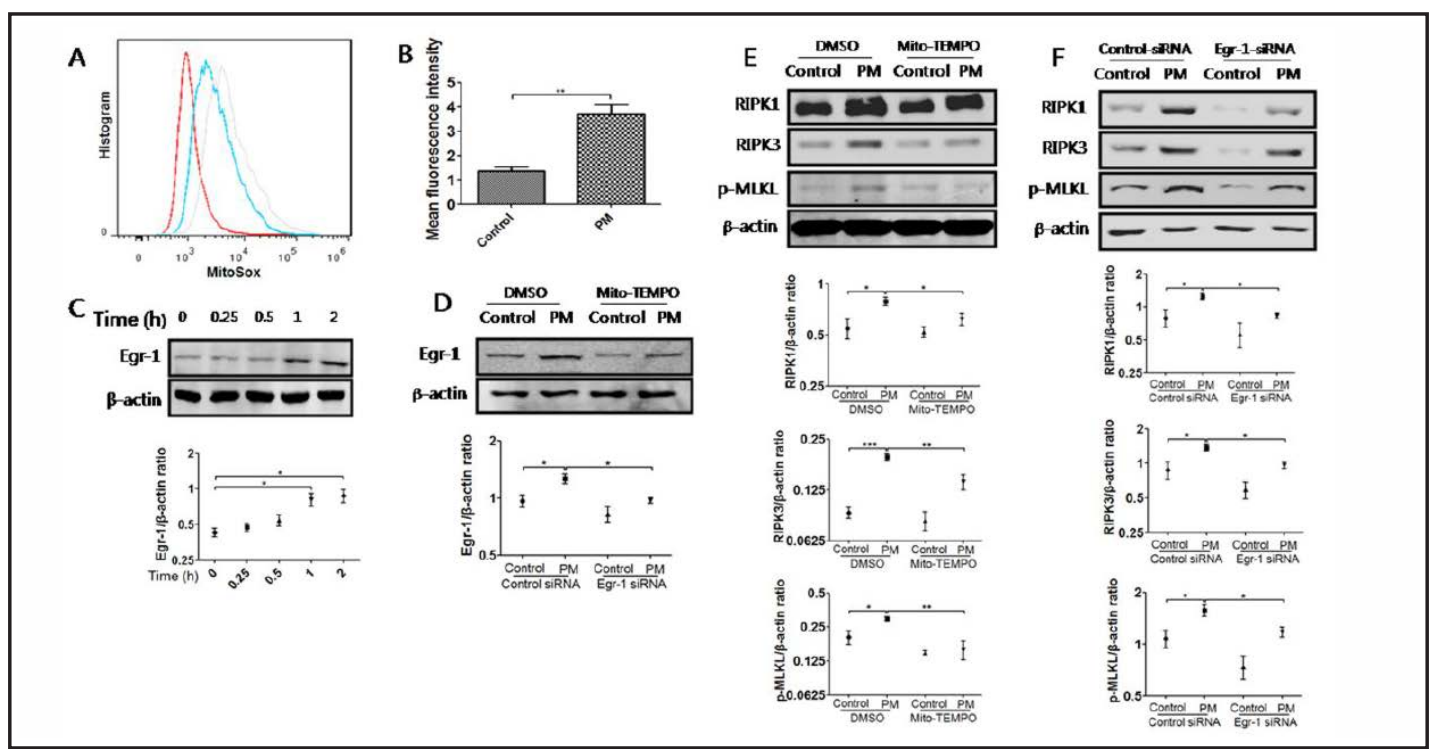

Fig. 5. MitoROS-dependent Egr-1 activation is involved in PM-induced necroptosis. (A-B) Cells were treated with PM $(100 \mu \mathrm{g} / \mathrm{ml})$ for $6 \mathrm{~h}$, and the level of mitoROS was determined. (A) Flow cytometry analysis of HBE cells were stained with mitoSOX (red, unstained; blue, control; gray, PM); (B) Quantification data of A. (C) Western blot analysis for time course (PM at $100 \mu \mathrm{g} / \mathrm{ml}$ for various times) of Egr-1 protein expression in HBE cells treated with PM. (D-E) Cells treated with PM $(100 \mu \mathrm{g} / \mathrm{ml})$ in the absence or presence of $10 \mu \mathrm{M}$ mito-TEMPO. (D) Western blot for PM-induced Egr-1 expression. (E) The levels of RIPK1, RIPK3, and Phospho-MLKL were determined by Western blots. (F) HBE cells were transfected with control-siRNA or Egr-1siRNA for $24 \mathrm{~h}$, and were treated with PM $(100 \mu \mathrm{g} / \mathrm{ml})$ for an additional $4 \mathrm{~h}$. (F) RIPK1, RIPK3, and p-MLKL protein expression were assessed by Western blots. The data are presented as the mean $\pm \mathrm{SEM}$. $* \mathrm{P}<0.05$, ** $\mathrm{P}<0.01$, and ${ }^{* * *} \mathrm{P}<0.001$.

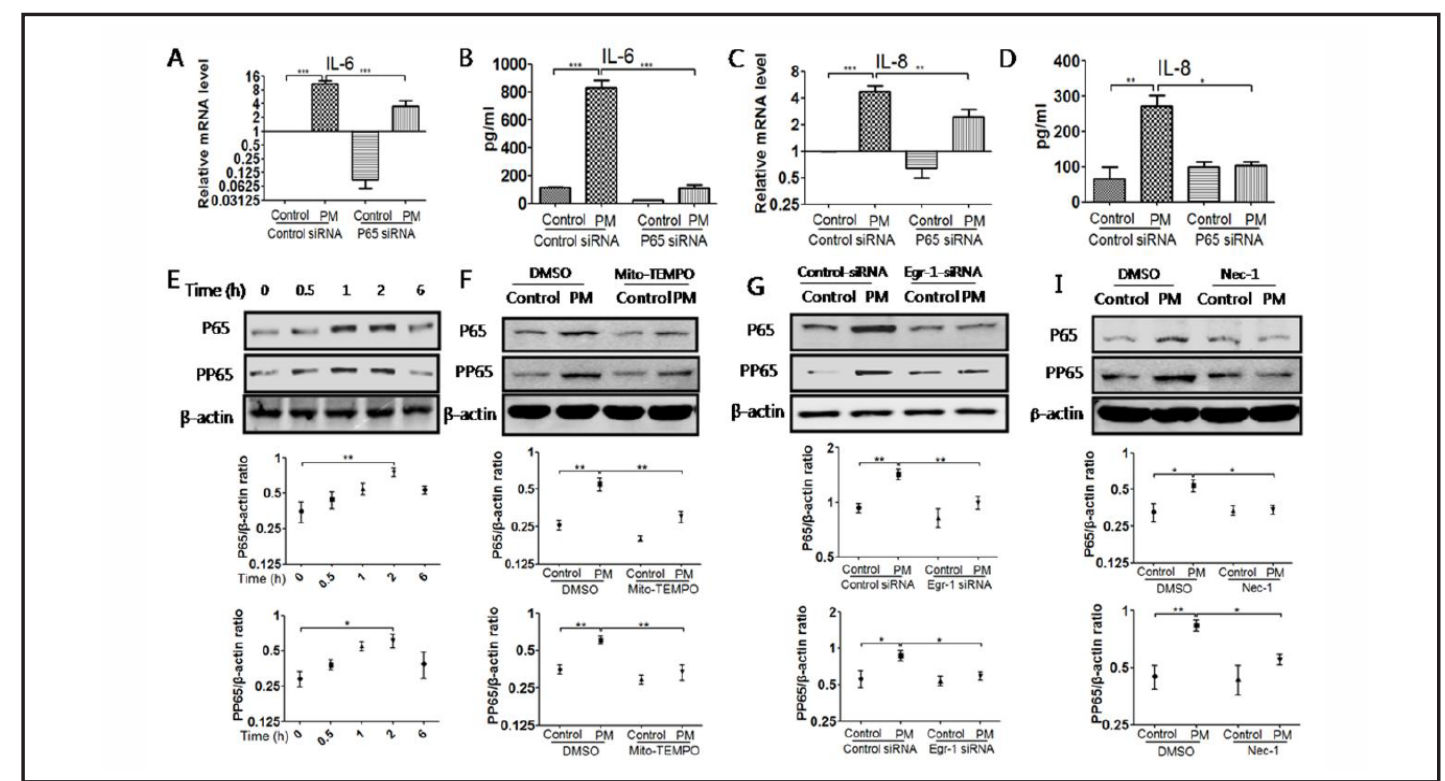

Fig. 6. NF- $\kappa B$ is critical for PM-induced inflammatory responses in HBE cells. (A-D) Cells were transfected with control-siRNA, Jun-siRNA or P65-siRNA for $24 \mathrm{~h}$, and then were treated with PM (100 $\mu \mathrm{g} / \mathrm{ml})$ for an additional $24 \mathrm{~h}$. The relative levels of IL6 (A) and IL8 (C) mRNA transcripts were measured by quantitative RT-PCR, and the protein levels of IL6 (B) and IL8 (D) in the culture supernatants were measured by ELISA. (E) Western blot analysis for time course (PM at $100 \mu \mathrm{g} / \mathrm{ml}$ for various times) of NF- $\kappa B$ (detected with p65 or phospho-p65 antibodies) protein expression in HBE cells treated with PM. (F) Cells were treated with PM

\section{KARGER}


$(100 \mu \mathrm{g} / \mathrm{ml})$ for $2 \mathrm{~h}$ in the absence or presence of $10 \mu \mathrm{M}$ mito-TEMPO to measure the level of NF- $\mathrm{KB}$. (G) Cells were transfected with control-siRNA or Egr-1-siRNA for $24 \mathrm{~h}$, and then were treated with PM $(100 \mu \mathrm{g} / \mathrm{ml})$ for $2 \mathrm{~h}$ to measure NF-KB. (I) Cells were incubated in the absence or presence of NEC-1, and then treated with PM $(100 \mu \mathrm{g} / \mathrm{ml})$ for with $2 \mathrm{~h}$ to measure the level of NF-KB. (F, G, I) The level of NF- $\mathrm{KB}$ was determined by Western blots. The data are presented as the mean \pm SEM. ${ }^{*} \mathrm{P}<0.05,{ }^{* *} \mathrm{P}<0.01$, and ${ }^{* * *} \mathrm{P}<0.001$.

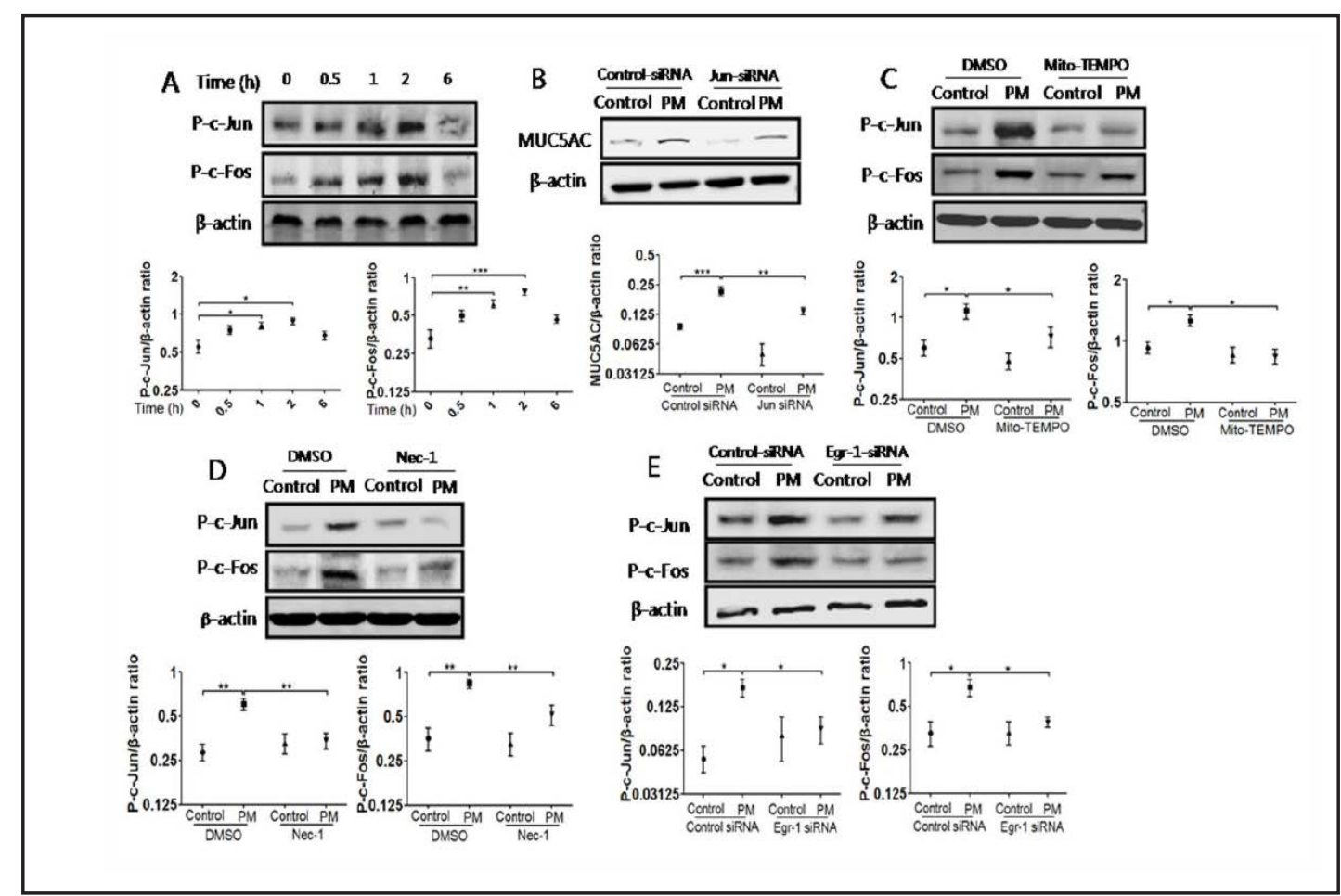

Fig. 7. AP-1 is critical for PM-induced expression of mucin MUC5AC in HBE cells. (A) Western blot analysis for time course (PM at $100 \mu \mathrm{g} / \mathrm{ml}$ for various times) of AP-1 detected with P-c-Jun and P-c-Fos protein expression in HBE cells treated with PM. (B) Cells were transfected with control-siRNA or Jun-siRNA for $24 \mathrm{~h}$, and then were treated with PM $(100 \mu \mathrm{g} / \mathrm{ml})$ without FBS for an additional $48 \mathrm{~h}$ to measure the protein of MUC5AC. (B) Levels of MUC5AC were measured by Western blot. (C) Cells were treated with PM (100 $\mu \mathrm{g}$ / $\mathrm{ml}$ ) for $2 \mathrm{~h}$ in the absence or presence of $10 \mu \mathrm{M}$ mito-TEMPO to measure the level of AP-1. (D) Cells were transfected with control-siRNA or Egr-1-siRNA for $24 \mathrm{~h}$, and then were treated with PM (100 $\mu \mathrm{g} / \mathrm{ml})$ for $2 \mathrm{~h}$ to measure the level of AP-1. (E) Cells were incubated in the absence or presence of NEC-1, and then were treated with PM $(100 \mu \mathrm{g} / \mathrm{ml})$ for with $2 \mathrm{~h}$ to measure the level of AP-1. (C, D, and E) The levels of AP-1 protein were detected with phospho-c-Jun and phospho-c-Fos antibodies, as determined by Western blots. The data are presented as the mean \pm SEM. $* \mathrm{P}<0.05,{ }^{* *} \mathrm{P}<0.01$, and ${ }^{* * *} \mathrm{P}<0.001$.

\section{AP-1 is critical for PM-induced expression of mucin MUC5AC in HBE cells}

To verify the role of AP1 in CSE-induced expression of MUC5AC, we detected AP-1 expression on PM exposure. In HBE cells, AP-1-related proteins (P-c-Jun and P-c-Fos) were increased in a time-dependent manner after PM exposure (Fig. 7A). Moreover, the inhibition of the AP-1 pathway by its specific siRNA markedly attenuated the PM-induced production of MUC5AC (Fig. 7B). We use mito-TEMPO to suppress mitoROS and further investigate the role of the mitoROS pathway. Interestingly, the expression of PM-induced AP-1 was significantly decreased (Fig. 7C). Again, genetic inhibition of Egr-1 by siRNA or Nec-1 treatment significantly decreased the PM-induced activation of the AP-1 pathway (Fig. 7D-E). These results suggest that PM exposure triggers the mitoROS/Egr-1/necroptosis pathway, which accordingly activates AP-1, as a signal to produce MUC5AC in airway epithelial cells. 


\section{Cellular Physiology Cell Physiol Biochem 2018;46:699-712 \begin{tabular}{c|c|c|} 
DOI: 10.1159/000488726 & O 2018 The Author(s). Published by S. Karger AG, Basel \\
www.karger.com/cpb
\end{tabular} \\ Xu et al.: Necroptosis Contributes to PM-Induced Airway Epithelial Injury}

\section{Discussion}

A growing body of evidence suggests that PM exposure leads to a greater incidence of respiratory diseases associated with increased morbidity and mortality. However, the cause of this condition is complex. Necroptosis is a regulated form of necrosis that features plasma membrane rupture, thereby releasing proinflammatory intracellular components. Classical necroptosis is characterized by RIP and its substrate MLKL activation, both of which are useful biomarkers for assessing necroptosis in vitro and in vivo [23]. When caspases are inhibited under certain physiological conditions, RIPK1 via the RIP-homotypic interaction motif (RHIM) interacts with downstream RIPK3 to form the necrosome to then recruit MLKL [24]. Activated MLKL oligomers eventually cause membrane rupture and release of DAMPs, which trigger inflammatory reactions and accelerate cell death $[25,26]$. Thus, necroptosis is recognized as a cause of inflammation and is linked to pathological conditions with an overt inflammatory signature [25]. Necroptosis execution depends on RIPK1, RIPK3, and MLKL activation, and can be blocked by these inhibitors. It has been recently reported that necroptosis plays an important role in the pathogenesis of pulmonary diseases, including COPD, lung cancer, infection, and sepsis [17]. In our study, necroptosis inhibitor Nec-1 and GSK'872 could decrease inflammation and alleviate mucus hyperproduction in airway epithelial cells induced by PM exposure. Nec-1 also reduced these pathologic features in mouse airways. Therefore, our in vitro and in vivo data demonstrate that airway epithelium necroptosis may play a pathogenic role in PM-induced pulmonary injury.

Oxidative stress is integral to the general inflammatory response, which occurs due to a metabolic imbalance due to excess production of ROS and reduced level of host antioxidant defences [27-29]. PM induced acute and chronic effects via an inflammatory mechanism of oxidative stress [30-32], and PM could play an important role in adverse respiratory effects through generating ROS in the respiratory tract [33]. Substantial evidence accumulated to show that reactive oxygen species (ROS) have long been considered to be a driving force for necroptosis [34-36]. A recent study showed that mitoROS promoted RIP1 autophosphorylation via modification of three crucial cysteine residues, and this phosphorylation event allowed efficient recruitment of RIP3 to RIP1 to form a functional necrosome for TNF-induced necroptosis [37]. In accordance with previous studies, we found that PM exposure induced mitoROS, and mitoROS mediated PM-induced necroptosis in HBE cells. Egr-1, also known as NGFI-A, krox-24, Zif-268, or TIS8, belongs to the immediate-early gene family and encodes a Cys2-His2-type zinc finger transcription factor [38]. In previous work, we found that Egr-1 played a negative role in PM-induced pulmonary injury in airway epithelium. We further found a positive interaction between mitoROS and Egr-1 activation, which in turn increase PM-induced necroptosis. Our data suggest that mitoROS and Egr-1 might be selected targets in PM-induced pulmonary diseases.

Several studies indicate that NF- $\kappa$ B plays a strong role in the initiation of inflammatory responses [39-41]. Recently, RIPK3, the critical biomarker for necroptosis, was shown to facilitate inflammation through NF- $\kappa B[26,42]$. Our data demonstrated that inhibiting necroptosis reduced the PM-induced pulmonary inflammation via the NF- $\kappa B$ pathway. Airway mucus hypersecretion may be considered to be an important pathological feature of chronic airway diseases, in that it clogs small airways, which impair respiration and contributes to recurrent infection and mortality, particularly in patients with more severe diseases. Mucins are the major component of mucus secretions, and MUC5AC is the primary mucin in human airways [43]. Previous studies demonstrated that activator protein-1 (AP-1), composed of homo- and heterodimers of c-Jun and c-Fos proteins, was the transcriptional activator of MUC5AC [44]. Thus, we first detected AP-1 expression in PM exposure. AP-1 was reported to mediate mucin transcription through two binding sites on $-3700 /-3337$ in the MUC5AC 5 '-flanking region [45]. Our results showed that inhibiting necroptosis was correlated with a decrease in mucus production through AP-1 pathway by PM exposure. As such, it is possible that RIPK1 interacts with its downstream RIPK3 to form the necrosome to recruit MLKL, in turn causing membrane rupture that releases DAMP, and facilitates NF- $\kappa \mathrm{B}$ to induce 


\section{Cellular Physiology Cell Physiol Biochem 2018;46:699-712 \begin{tabular}{l|l} 
DOI: 10.1159/000488726 & a 2018 The Author(s). Published by S. Karger AG, Basel \\
www.karger.com/cpb
\end{tabular}

inflammatory cytokines and AP-1 to induce mucus production in response to PM exposure (Fig. 8).

We found that necroptosis was required for the release of PM-induced inflammatory cytokines and mucin MUC5AC. The present study had limitations, though, in terms of what we do about solid control groups. Numerous reports classify PM by particle size, but it may oversimplify or overlook the molecular makeup of the PM sample. PM is a complex mixture containing components such as carbonaceous core, PAHs, quinones, metals, endotoxins and others [9]. It is difficult to know what the main substance in the induction of the inflammatory response may be. We use PBS or saline as controls for PM treatment (PM is generally dispersed in sterile saline or PBS), similar to previous studies $[4,8,46,47]$. It might be better to add an a-specific stimulus as a control which might enhance the robustness of our findings.

\section{Conclusion}

In summary, we demonstrate a novel mechanism of how PM induces mitoRos and Egr-1 signaling, which leads to necroptosis in pulmonary epithelial cells; ultimately, they activate two distinct signaling cascades, NF- $\kappa \mathrm{B}$ and AP-1 pathways, to induce airway inflammation and mucus hyperproduction. Our results suggest that necroptosis contributes to the pathogenesis of PMinduced pulmonary injury, so that related strategies targeting this pathway may lead to novel therapies for airway disorders or disease exacerbations associated with airborne particulate pollution.

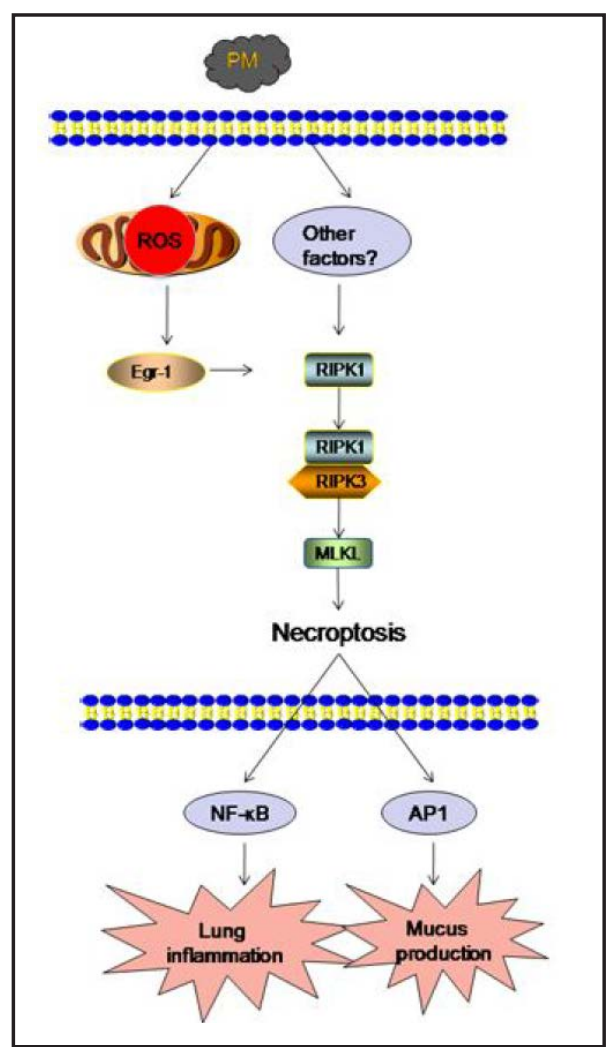

Fig. 8. Schematic representation of the mechanisms of PM-induced necroptosis in the differential regulation of subsequent inflammation and mucus hyperproduction in airway epithelium. PM exposure initially triggers production of mitoROS and elicits Egr-1, which induces RIPK1, RIPK3, and Phospho-MLKL; this then regulates inflammation and mucus hyperproduction, partially through modulation of two distinct signaling cascades, NF- $\kappa$ B and AP-1 pathways.

\section{Acknowledgements}

Financial support was provided by the Key Project of Chinese National Programs for Fundamental Research and Development (973 program, 2015CB553405), General Projects of the NSFC (81490532, 81130001 and 81370142), the National Key Technologies R\&D Program for the 12th Five-year Plan (2012BAI05B01), and the project from the National Clinical Research Center of China for Respiratory Disease.

\section{Disclosure Statement}

The authors declare that there is no conflict of interest regarding publication of this manuscript. 


\section{Cellular Physiology Cell Physiol Biochem 2018;46:699-712 \begin{tabular}{l|l} 
DOI: 10.1159/000488726 & Ond 2018 The Author(s). Published by S. Karger AG, Basel \\
www.karger.com/cpb
\end{tabular} and biochemistry}

\section{References}

1 Wang R, Xiao X, Shen Z, Cao L, Cao Y: Airborne fine particulate matter causes murine bronchial hyperreactivity via MAPK pathway-mediated M3 muscarinic receptor upregulation. Environ Toxicol 2017;32:371-381.

2 Sacks JD, Stanek LW, Luben TJ, Johns DO, Buckley BJ, Brown JS, Ross M: Particulate matter-induced health effects: who is susceptible? Environ Health Perspect 2011;119:446-454.

3 Guan WJ, Zheng XY, Chung KF, Zhong NS: Impact of air pollution on the burden of chronic respiratory diseases in China: time for urgent action. Lancet (London, England) 2016;388:1939-1951.

-4 Chen ZH, Wu YF, Wang PL, Wu YP, Li ZY, Zhao Y, Zhou JS, Zhu C, Cao C, Mao YY, Xu F, Wang BB, Cormier SA, Ying SM, Li W, Shen HH: Autophagy is essential for ultrafine particle-induced inflammation and mucus hyperproduction in airway epithelium. Autophagy 2016;12:297-311.

5 Traboulsi H, Guerrina N, Iu M, Maysinger D, Ariya P, Baglole CJ: Inhaled Pollutants: The Molecular Scene behind Respiratory and Systemic Diseases Associated with Ultrafine Particulate Matter. Int J Mol Sci $2017 ; 18$

6 Liu S, Zhou Y, Liu S, Chen X, Zou W, Zhao D, Li X, Pu J, Huang L, Chen J, Li B, Liu S, Ran P: Association between exposure to ambient particulate matter and chronic obstructive pulmonary

disease: results from a cross-sectional study in China. Thorax 2016

7 Jacquemin B, Siroux V, Sanchez M, Carsin AE, Schikowski T, Adam M, Bellisario V, Buschka A,Bono R, Brunekreef B, Cai Y, Cirach M, Clavel-Chapelon F, Declercq C, de Marco R, de Nazelle A, Ducret-Stich RE, Ferretti VV, Gerbase MW, Hardy R, Heinrich J, Janson C, Jarvis D, Al Kanaani Z, Keidel D, Kuh D, Le Moual N, Nieuwenhuijsen MJ, Marcon A, Modig L, Pin I, Rochat T, Schindler C, Sugiri D, Stempfelet M, Temam S, Tsai MY, Varraso R, Vienneau D, Vierkotter A, Hansell AL, Kramer U, Probst-Hensch NM, Sunyer J, Kunzli N, Kauffmann F: Ambient air pollution and adult asthma incidence in six European cohorts (ESCAPE). Environ Health Perspect 2015;123:613-621.

-8 Vignal C, Pichavant M, Alleman LY, Djouina M, Dingreville F, Perdrix E, Waxin C, Ouali Alami A, GowerRousseau C, Desreumaux P, Body-Malapel M: Effects of urban coarse particles inhalation on oxidative and inflammatory parameters in the mouse lung and colon. Part Fibre Toxicol 2017;14:46.

-9 Rumelhard M, Ramgolam K, Hamel R, Marano F, Baeza-Squiban A: Expression and role of EGFR ligands induced in airway cells by PM2.5 and its components. Eur Respir J 2007;30:1064-1073.

10 Hanson B: Necroptosis: A new way of dying? Cancer Biol Ther 2016;17:899-910.

11 Linkermann A, Green DR: Necroptosis. N Engl J Med 2014;370:455-465.

12 Pasparakis M, Vandenabeele P: Necroptosis and its role in inflammation. Nature 2015;517:311-320.

13 Moreno-Gonzalez G, Vandenabeele P, Krysko DV: Necroptosis: A Novel Cell Death Modality and Its Potential Relevance for Critical Care Medicine. Am J Respir Crit Care Med 2016;194:415-428.

14 Kaczmarek A, Vandenabeele P, Krysko DV: Necroptosis: the release of damage-associated molecular patterns and its physiological relevance. Immunity 2013;38:209-223.

15 Pouwels SD, Zijlstra GJ, van der Toorn M, Hesse L, Gras R, Ten Hacken NH, Krysko DV, Vandenabeele P, de Vries M, van Oosterhout AJ, Heijink IH, Nawijn MC: Cigarette smoke-induced necroptosis and DAMP release trigger neutrophilic airway inflammation in mice. Am J Physiol Lung Cell Mol Physiol 2016;310:L377-386.

-16 Szobi A, Rajtik T, Adameova A: Effects of necrostatin-1, an inhibitor of necroptosis, and its inactive analogue Nec-1i on basal cardiovascular function. Physiol Res 2016;65:861-865.

17 Mizumura K, Maruoka S, Gon Y, Choi AM, Hashimoto S: The role of necroptosis in pulmonary diseases. Respir Investig 2016;54:407-412.

18 Mizumura K, Cloonan SM, Nakahira K, Bhashyam AR, Cervo M, Kitada T, Glass K, Owen CA, Mahmood A, Washko GR, Hashimoto S, Ryter SW, Choi AM: Mitophagy-dependent necroptosis contributes to the pathogenesis of COPD. J Clin Invest 2014;124:3987-4003.

19 Duprez L, Takahashi N, Van Hauwermeiren F, Vandendriessche B, Goossens V, Vanden Berghe T, Declercq W, Libert C, Cauwels A, Vandenabeele P: RIP kinase-dependent necrosis drives lethal systemic inflammatory response syndrome. Immunity 2011;35:908-918.

20 Zec M, Srdic-Rajic T, Krivokuca A, Jankovic R, Todorovic T, Andelkovic K, Radulovic S: Novel selenosemicarbazone metal complexes exert anti-tumor effect via alternative, caspase-independent necroptotic cell death. Med Chem (Los Angeles) 2014;10:759-771. 


\section{Cellular Physiology Cell Physiol Biochem 2018;46:699-712

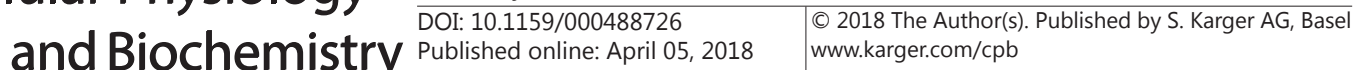 and Biochemistry}

-21 Myou S, Leff AR, Myo S, Boetticher E, Tong J, Meliton AY, Liu J, Munoz NM, Zhu X: Blockade of inflammation and airway hyperresponsiveness in immune-sensitized mice by dominant-negative phosphoinositide 3-kinase-TAT. J Exp Med 2003;198:1573-1582.

22 McMillan SJ, Bishop B, Townsend MJ, McKenzie AN, Lloyd CM: The absence of interleukin 9 does not affect the development of allergen-induced pulmonary inflammation nor airway hyperreactivity. J Exp Med 2002;195:51-57.

23 He S, Huang S, Shen Z: Biomarkers for the detection of necroptosis. Cell Mol Life Sci 2016;73:2177-2181.

-24 Li J, McQuade T, Siemer AB, Napetschnig J, Moriwaki K, Hsiao YS, Damko E, Moquin D, Walz T, McDermott A, Chan FK, Wu H: The RIP1/RIP3 necrosome forms a functional amyloid signaling complex required for programmed necrosis. Cell 2012;150:339-350.

25 Kopalli SR, Kang TB, Koppula S: Necroptosis inhibitors as therapeutic targets in inflammation mediated disorders - a review of the current literature and patents. Expert Opin Ther Pat 2016;26:1239-1256.

26 Moriwaki K, Balaji S, McQuade T, Malhotra N, Kang J, Chan FK: The necroptosis adaptor RIPK3 promotes injury-induced cytokine expression and tissue repair. Immunity 2014;41:567-578.

27 Chan YL, Saad S, Pollock C, Oliver B, Al-Odat I, Zaky AA, Jones N, Chen H: Impact of maternal cigarette smoke exposure on brain inflammation and oxidative stress in male mice offspring. Sci Rep 2016;6:25881.

28 Du X, Shi Z, Peng Z, Zhao C, Zhang Y, Wang Z, Li X, Liu G, Li X: Acetoacetate induces hepatocytes apoptosis by the ROS-mediated MAPKs pathway in ketotic cows. J Cell Physiol 2017;232:3296-3308.

29 Song Y, Li N, Gu J, Fu S, Peng Z, Zhao C, Zhang Y, Li X, Wang Z, Li X, Liu G: beta-Hydroxybutyrate induces bovine hepatocyte apoptosis via an ROS-p38 signaling pathway. J Dairy Sci 2016;99:9184-9198.

30 Su R, Jin X, Zhang W, Li Z, Liu X, Ren J: Particulate matter exposure induces the autophagy of macrophages via oxidative stress-mediated PI3K/AKT/mTOR pathway. Chemosphere 2017;167:444-453.

-31 Risom L, Moller P, Loft S: Oxidative stress-induced DNA damage by particulate air pollution. Mutat Res 2005;592:119-137.

-32 Nemmar A, Karaca T, Beegam S, Yuvaraju P, Yasin J, Hamadi NK, Ali BH: Prolonged Pulmonary Exposure to Diesel Exhaust Particles Exacerbates Renal Oxidative Stress, Inflammation and DNA Damage in Mice with Adenine-Induced Chronic Renal Failure. Cell Physiol Biochem 2016;38:1703-1713.

-33 Li N, Wang M, Bramble LA, Schmitz DA, Schauer JJ, Sioutas C, Harkema JR, Nel AE: The adjuvant effect of ambient particulate matter is closely reflected by the particulate oxidant potential. Environ Health Perspect 2009;117:1116-1123.

34 Liang W, Chen M, Zheng D, Li J, Song M, Zhang W, Feng J, Lan J: The Opening of ATP-Sensitive K+ Channels Protects H9c2 Cardiac Cells Against the High Glucose-Induced Injury and Inflammation by Inhibiting the ROS-TLR4-Necroptosis Pathway. Cell Physiol Biochem 2017;41:1020-1034.

-35 Locatelli SL, Cleris L, Stirparo GG, Tartari S, Saba E, Pierdominici M, Malorni W, Carbone A, Anichini A, Carlo-Stella C: BIM upregulation and ROS-dependent necroptosis mediate the antitumor effects of the HDACi Givinostat and Sorafenib in Hodgkin lymphoma cell line enografts. Leukemia 2014;28:1861-1871.

-36 Xie X, Zhao Y, Ma CY, Xu XM, Zhang YQ Wang CG, Jin J, Shen X, Gao JL, Li N, Sun ZJ, Dong DL: Dimethyl fumarate induces necroptosis in colon cancer cells through GSH depletion/ROS increase/MAPKs activation pathway. Br J Pharmacol 2015;172:3929-3943.

-37 Zhang Y, Su SS, Zhao S, Yang Z, Zhong CQ Chen X, Cai Q, Yang ZH, Huang D, Wu R, Han J: RIP1 autophosphorylation is promoted by mitochondrial ROS and is essential for RIP3 recruitment into necrosome. Nat Commun 2017;8:14329.

-38 Tian J, Li Z, Han Y, Jiang T, Song X, Jiang G: The progress of early growth response factor 1 and leukemia. Intractable Rare Dis Res 2016;5:76-82.

39 Jung HS, Joo JD, Kim DW, In JH, Roh M, Jeong JT, Noh SJ, Choi JW: Effect of milrinone on the inflammatory response and NF-kB activation in renal ischemia-reperfusion injury in mice. Korean J Anesthesiol 2014;66:136-142.

40 Limtrakul P, Yodkeeree S, Pitchakarn P, Punfa W: Suppression of Inflammatory Responses by Black Rice Extract in RAW 264.7 Macrophage Cells via Downregulation of NF-kB and AP-1 Signaling Pathways. Asian Pac J Cancer Prev 2015;16:4277-4283.

41 Sun X, Yuan X, Chen L, Wang T, Wang Z, Sun G, Li X, Li X, Liu G: Histamine Induces Bovine Rumen Epithelial Cell Inflammatory Response via NF-kappaB Pathway. Cell Physiol Biochem 2017;42:1109-1119. 


\section{Cellular Physiology Cell Physiol Biochem 2018;46:699-712 \begin{tabular}{l|l} 
DOI: 10.1159/000488726 \\
and Biochemistry
\end{tabular} $\begin{aligned} & \text { O 2018 The Author(s). Published by S. Karger AG, Basel } \\
& \text { www.karger.com/cpb }\end{aligned}$ \\ \begin{tabular}{ll} 
Published onlıne: ApriI 05, $2018 \quad$ www.karger.com/cpb \\
\hline Xu et al: Necroptosis Contributes to PM-Induced Airway Epithelial Injury
\end{tabular}}

-42 Kaiser WJ, Upton JW, Mocarski ES: Receptor-interacting protein homotypic interaction motif-dependent control of NF-kappa B activation via the DNA-dependent activator of IFN regulatory factors. J Immunol 2008;181:6427-6434.

43 Wang X, Li Y, Luo D, Wang X, Zhang Y, Liu Z, Zhong N, Wu M, Li G: Lyn regulates mucus secretion and MUC5AC via the STAT6 signaling pathway during allergic airway inflammation. Sci Rep 2017;7:42675.

-44 Shen H, Yoshida H, Yan F, Li W, Xu F, Huang H, Jono H, Li JD: Synergistic induction of MUC5AC mucin by nontypeable Haemophilus influenzae and Streptococcus pneumoniae. Biochem Biophys Res Commun 2008;365:795-800.

-45 Gensch E, Gallup M, Sucher A, Li D, Gebremichael A, Lemjabbar H, Mengistab A, Dasari V, Hotchkiss J, Harkema J, Basbaum C: Tobacco smoke control of mucin production in lung cells requires oxygen radicals AP-1 and JNK. J Biol Chem 2004;279:39085-39093.

46 Wang P, You D, Saravia J, Shen H, Cormier SA: Maternal exposure to combustion generated PM inhibits pulmonary Th1 maturation and concomitantly enhances postnatal asthma development in offspring. Part Fibre Toxicol 2013;10:29.

47 Zhang X, Zhong W, Meng Q Lin Q, Fang C, Huang X, Li C, Huang Y, Tan J: Ambient PM2.5 exposure exacerbates severity of allergic asthma in previously sensitized mice. J Asthma 2015;52:785-794. 